\title{
'Lilleland' Peach: A High Case-yield Processing Clingstone Peach for the 'Halford' Maturity Period
}

\author{
Thomas M. Gradziel ${ }^{1}$ and Mary Ann Thorpe \\ Department of Plant Sciences, University of California, 1 Shields Avenue, \\ Davis, CA, 95616
}

\author{
Diane M. Barrett \\ Department of Food Science, One Shields Avenue, University of California, \\ Davis, CA, 95616
}

The clingstone peach [Prunus persica $(\mathrm{L}$.) Batsch] cultivar Lilleland combines field productivity with improved processing quality, including a small endocarp or pit, freedom from undesirable fruit pit staining, and reduced incidence of pit fragments remaining in processed fruit. 'Lilleland' ripens with the widely planted but difficult to process cultivar Halford. 'Lilleland' originated from a series of crosses combining traditional, well-adapted California germplasm with novel germplasm from the freestone peach 'Elberta' and the clingstone nectarine PI 292557. In long-term commercial evaluations, fruit have demonstrated good firmness, color, shape, and productivity. Tree form is upright-spreading with vigor and branch architecture similar to 'Halford'. Leaves are medium to dark green with reniform leaf glands. Flowers are pink, showy, and medium in size.

\section{Origin}

Since its introduction in 1921, 'Halford' has become one of the most extensively planted processing peach cultivars in California (Gradziel et al., 1993). However, high temperatures during fruit development often promote a red anthocyanin staining of the fruit pit cavity with an associated increase in pit fragments remaining in fruit after processing. The red anthocyanins turn brown when heat-processed, staining both the processed fruit and syrup. Both stained and fragmentcontaining fruit need to be sorted out, which can greatly reduce final processed fruit case yields. The cultivar Lilleland was developed as a replacement for 'Halford' and demonstrates improved processing quality while retaining similar size, firmness, productivity, and maturity. 'Lilleland' was selected in 1988 from open-pollinated seedlings of the breeding selection 'R13-33', which had both

Received for publication 6 Sept. 2007. Accepted for publication 17 Oct. 2007.

${ }^{1}$ To whom reprint requests should be addressed; e-mail tmgradziel@ucdavis.edu breeding selection 'N,23-9W' and 'Ross' as parents (Fig. 1). Breeding selection 'N,239W' was derived from traditional canning peach germplasm, which has proven well adapted to California Central Valley environments but deficient in meeting market demands for improved processed fruit quality (Gradziel et al., 1993). 'Ross' was bred to integrate the traditional regionally adapted and productive traits of ' $\mathrm{GH}, 18-4$ ' and 'Dix,18A-2' with high fruit quality from the freestone peach 'Elberta' and the clingstone nectarine PI 292557. Since its release in the mid-1980s, 'Ross', which ripens 2 weeks before 'Halford', has become the most heavily planted California processing peach and its uniformly golden yellow fruit have become the idiotype for canned fruit quality (Tourjee et al., 1998). 'Lilleland' is the result of a breeding program to transfer productivity and improved processing quality to later season cultivars and was originally evaluated at Davis, CA, as breeding selection ' $\mathrm{F} 10 \mathrm{EN}$, 6-27'. Selection 'F10EN,6-27' was subsequently tested at plots established in 1992 at Winters and Davis, CA, in the Sacramento Valley and at Parlier, CA, in the San Joaquin Valley, and in 1998 at multiple grower evaluation plots in the Sacramento and San Joaquin Valleys. Based on its very positive evaluations, selection 'F10EN,6-27' has been patented and released as the processing peach cultivar Lilleland after the late Professor Omund Lilleland of the Department of Pomology, University of California, Davis, $\mathrm{CA}$, who did much of the initial plant nutrient studies for processing peach.

\section{Description}

'Lilleland' produces nonmelting clingstone peach fruit of medium size with a round shape and without a pronounced fruit tip (Fig. 2). Fruit epidermis has a uniform goldenyellow color with up to $50 \%$ red blush and a fine, short, matted pubescence. Flesh is bright yellow to yellow-gold. The pit is medium to small in size and has remained free from the red color and high incidence of pit fragments. The tree is upright-spreading with vigor similar to 'Halford'. Branch architecture is similar to 'Halford', although often with a denser canopy. Flowers are pink, nonshowy, and medium in size. Leaves are medium to dark green, similar in size to Halford with reniform leaf glands.

\section{Performance}

Trees were evaluated from 1997 to 2007 under standard commercial conditions in the Sacramento and San Joaquin Valleys. Trees produce a medium to high crop, comparable to 'Halford'. 'Lilleland' bloom was uniform and abundant when chilling hours were above $700 \mathrm{~h}$ (using the Utah model of Byrne and Bacon, 1992) as occurred in all Central Valley test sites and years. Bloom time at Central Valley commercial production sites was early in relation to other commercial cling peach cultivars, being similar to 'Ross'. 'Lilleland' fruit were fully clingstone and nonmelting. Fully ripe fruit, as determined by a lack of visible green pigmentation on the fruit epidermis, showed a uniform yellowgold primary ground color with from $10 \%$ to $50 \%$ red blush. Fruit skin had a fine, short, and netted pubescence with no observed tendency to crack. Some split pits occur in low crop years, although at rates similar to 'Halford'. Fruit flesh (mesocarp) firmness was comparable to 'Halford' and within the desired range for canning (Table 1). Fruit mass and dry weight to fresh weight ratio were also similar 'Halford' when thinned using recommendations developed for the 'Halford' cultivar (California Canning Peach Association, 2005) to achieve fruit with commercially desirable diameters of 60.33 $\mathrm{mm}$ or greater. The fruit stone or pit was significantly smaller than 'Halford', contributing to an improved final case yield of processed fruit. In addition, 'Lilleland' showed no tendency toward the development of undesirable red anthocyanin staining of the fruit pit cavity and significantly fewer fruit with pit fragments in processed fruit. The fruit of 'Lilleland' also consistently demonstrated a broad and moderately deep stem cavity necessary for the proper alignment of fruit during torque pitting and processing. Processed flesh color "a" and hue values (Table 1) were in the desirable yellow to yellow-gold range (Gradziel, 1994; Tourjee et al., 1998), being less orange than 'Halford' and comparable to 'Ross', which has become the fruit color idiotype for the California industry.

\section{Availability}

'Lilleland' is available as a patented (US Plant Patent 13028) cultivar with licenses granted through the University of California Technology Transfer Services, 1850 Research Park Drive, Suite 100, Davis, CA 95618-6134. Propagation material is distributed as registered virus-tested sources through the Foundation Plant Service, University of California, 1 Shields Avenue, Davis, CA 95616. 


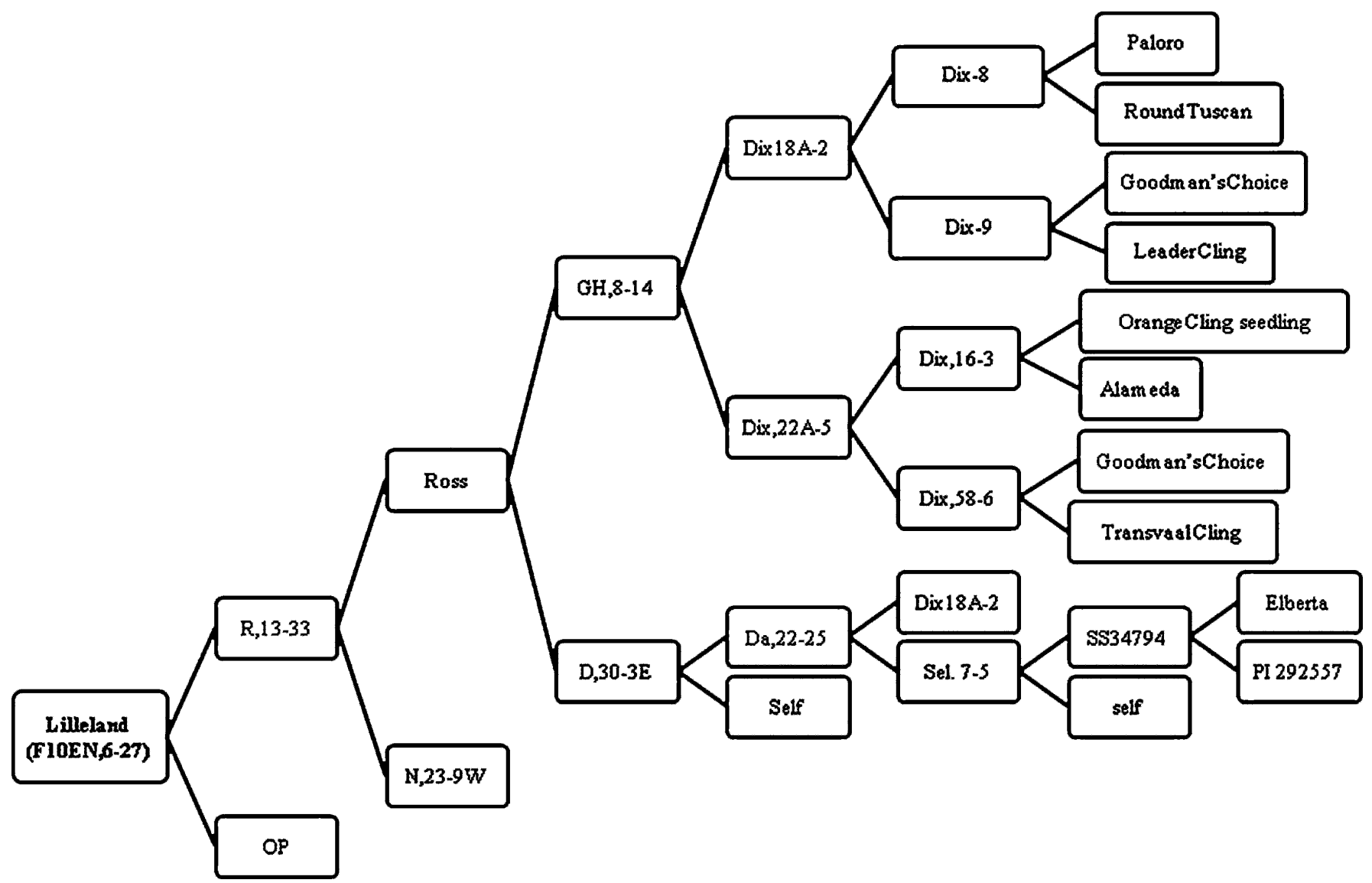

Fig. 1. Pedigree of 'Lilleland' peach. Seed parent is presented at the top.
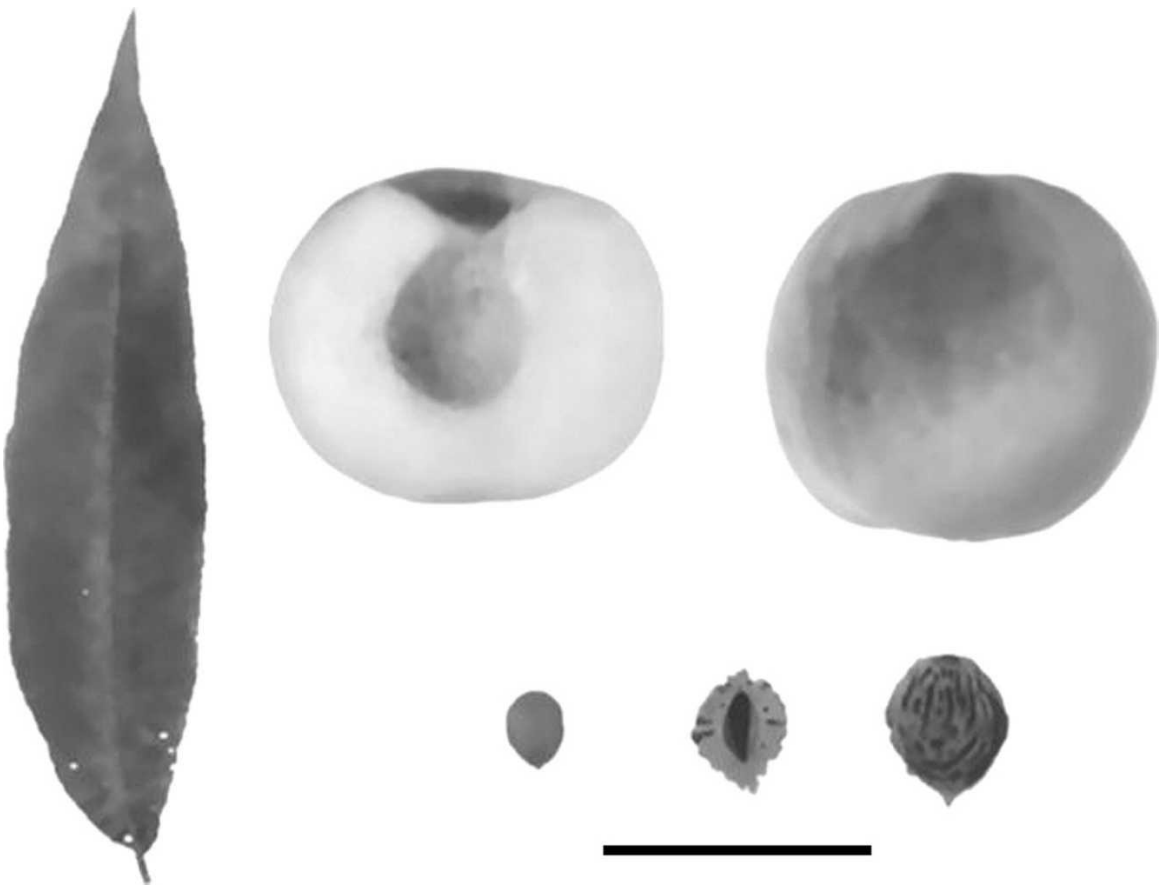

Fig. 2. Leaf, fruit, and stone morphology of 'Lilleland' peach $(\mathrm{bar}=5 \mathrm{~cm})$.

\section{Literature Cited}

Byrne, D.H. and T.A. Bacon. 1992. Chilling estimation: Its importance and estimation. The Texas Horticulturist 18:5,8-9.

California Canning Peach Association. 2005. Cling peach almanac, p. 7. Sacramento, CA.
Gradziel, T.M. 1994. Changes in susceptibility to brown rot with ripening in three clingstone peach genotypes. J. Amer. Soc. Hort. Sci. 119:101-105.

Gradziel, T.M., W. Beres, and K. Pelletreau. 1993. Inbreeding in California canning clingstone peach cultivars. Fruit Varieties J 47:160-168.
Table 1. Performance of 'Lilleland' clingstone, processing peach as compared with the similarly ripening California cultivar Halford. ${ }^{z}$

\begin{tabular}{lcc}
\hline & Lilleland & Halford \\
\hline $\begin{array}{l}\text { Raw fruit mass } \\
\text { (g fresh weight) }\end{array}$ & $129.5 \mathrm{a}$ & $132.1 \mathrm{a}$ \\
$\begin{array}{l}\text { Stone (endocarp) mass } \\
\text { (g dry weight) }\end{array}$ & $5.26 \mathrm{a}$ & $6.40 \mathrm{~b}$ \\
$\begin{array}{l}\text { Raw fruit } \\
\quad \text { firmness (kg) }\end{array}$ & $7.09 \mathrm{a}$ & $6.79 \mathrm{a}$ \\
$\begin{array}{l}\text { Fruit dry weight/fresh } \\
\quad \text { weight ratio }\end{array}$ & $0.16 \mathrm{a}$ & $0.17 \mathrm{a}$ \\
$\begin{array}{l}\text { Processed flesh } \\
\text { color "a" value }\end{array}$ & $2.9 \mathrm{a}$ & $4.9 \mathrm{~b}$ \\
$\begin{array}{l}\text { Processed flesh } \\
\quad \text { color "hue" value }\end{array}$ & $88.4 \mathrm{a}$ & $83.1 \mathrm{~b}$ \\
$\begin{array}{l}\text { Proportion with } \\
\text { red staining }\end{array}$ & $0.00 \mathrm{a}$ & $0.63 \mathrm{~b}$ \\
$\begin{array}{l}\text { Proportion with } \\
\text { shell fragments }\end{array}$ & $0.03 \mathrm{a}$ & $0.28 \mathrm{~b}$ \\
\hline
\end{tabular}

${ }^{\mathrm{z}}$ Mean separation performed within each row by Duncan's multiple range test, $P=0.05$ from a sample size of 50 fruit randomly harvested from tenth leaf trees thinned to achieve fruit diameters of 60.33 or greater in $95 \%$ of fruit.

${ }^{y}$ Fruit firmness was measured with a MagnessTaylor (Hunter Spring, Hatfield, PA) firmness tester using an 8-mm tip with fruit epidermis removed. ${ }^{x}$ CIELAB 1976 L*a*b* color space determined using a Minolta 2000L spectrophotometer combined with Minolta WinShades 1.1 color analysis software (Konica-Minolta, Ramsey, NJ).

Tourjee, K.R., D.M. Barrett, M.V. Romero, and T.M. Gradziel. 1998. Measuring flesh color variability among processing clingstone peach genotypes differing in carotenoid composition. J. Amer. Soc. Hort. Sci. 123:433-437. 